\title{
CÉLESTIN FREINET, LA ESCRITURA EN LIBERTAD Y EL PERIÓDICO ESCOLAR: UN MODELO DE INNOVACIÓN EDUCATIVA EN LA PRIMERA MITAD DEL SIGLO 20
}

\author{
José González-Monteagudo \\ Universidad de Sevilla, España
}

\section{$\cos 8$}

\section{CÉLESTIN FREINET, A ESCRITA EM LIBERDADE E O PERIÓDICO ESCOLAR: UM MODELO DE INOVAÇÃO EDUCATIVA NA PRIMEIRA METADE DO SÉCULO 20}

\section{Resumo}

Este artigo apresenta uma discussão sobre a escrita e os periódicos escolares no contexto da pedagogia de Freinet, no período histórico da primeira metade do século 20. Centra-se, a partir da história cultural, na relação entre a criação das técnicas de Freinet e a sociedade e culturas europeias. O modelo de Freinet se caracteriza pelo seu enfoque educativo inovador e seu progressismo social. Também se discute a importância da escrita na obra de Freinet, e no próprio modelo pedagógico, como elemento central de um novo paradigma sobre a criança, a aprendizagem e a escola. Finalmente, se discute o tema específico dos periódicos escolares e a influência de Freinet nesse âmbito.

Palavras-chave: Célestin Freinet, inovação educativa, periódico escolar, escrita infantil, escola ativa.

\section{CÉLESTIN FREINET, FREE WRITING AND THE SCHOOL JOURNAL: A MODEL OF PROGRESSIVE EDUCATION IN THE FIRST HALF OF THE 20TH CENTURY}

\begin{abstract}
This paper discusses on writing and the schools journals, within the context of Freinet's Pedagogy, regarding the historical period of the first half of the 20th century. It is paid special attention, from the viewpoint of cultural history, to the relations between the origins of Freinet's methods and European culture and society. The Freinet's approach is characterized by innovation in the educational fields as well as social progressivism. Also it is discussed the importance of writing in Freinet's broad contributions, and particularly regarding his educational model, as a central feature of a new paradigm on children, learning, and schools. Finally it is presented a discussion on school journals ant the influence of Freinet in this field.

Key-words: Célestin Freinet, progressive education, school journal, writing in children, new schools.
\end{abstract}




\title{
CÉLESTIN FREINET, LA ESCRITURA EN LIBERTAD Y EL PERIÓDICO ESCOLAR: UN MODELO DE INNOVACIÓN EDUCATIVA EN LA PRIMERA MITAD DEL SIGLO 20
}

\begin{abstract}
Resumen
Este artículo presenta una discusión sobre la escritura y los diarios escolares, en el contexto de la pedagogía Freinet, dentro del período histórico de la primera mitad del siglo 20. Se presta especial atención, desde el punto de la historia cultural, a la relación entre la creación de las técnicas Freinet y la sociedad y cultura europeas. El modelo de Freinet se caracteriza por su enfoque educativo innovador y su progresismo social. También se discute la importancia de la escritura en la obra de Freinet y en el propio modelo pedagógico, como elemento central de un nuevo paradigma sobre el niño, el aprendizaje y la escuela. Finalmente, se discute el tema específico de los diarios escolares y la influencia de Freinet en este ámbito.

Palabras-clave: Célestin Freinet, innovación educativa, diario escolar, escritura infantil, escuela activa.
\end{abstract}

\section{CÉLESTIN FREINET, L'ÉCRITURE EN LIBERTÉ ET LE JOURNAL SCOLAIRE: UNE APPROCHE D'INNOVATION ÉDUCATIVE DANS LA PREMIĖRE MOITIÉ DU 20ème SIĖCLE}

\section{Résume}

Cet article présente une discussion sur l'écriture et les jour aux scolaires, dans le contexte de la pédagogie Freinet, par rapport à la période historique de la première moitié du 20ème siècle. On prête spécial attention, depuis le point de vue de l'histoire culturelle, à la relation entre les origines des Techniques Freinet et la société et culture européennes. L'approche de Freinet à à voir avec l'innovation éducative et le progressisme social. On présente aussi un commentaire sur l'importance de l'écriture dans l'œuvre de Freinet et dans la modèle pédagogique proposé, en tant que dimension centrale d'un nouveau paradigme sur les enfants, l'apprentissage et les écoles. Finalement on discute sur les journaux scolaires et l'influence de Freinet dans ce domain.

Mots-clé: Célestin Freinet, innovation éducative, journal scolaire, écriture des enfants, école nouvelle. 


\section{Contexto histórico y biográfico de Freinet y sus técnicas}

élestin Freinet (1896-1966) nació en una aldea de los Alpes Marítimos del sur de Francia. Sus orígenes son rurales. De este ambiente extrae el pedagogo galo muchas de sus imágenes pedagógicas. Freinet se vio obligado a interrumpir los estudios de Magisterio y fue herido en un pulmón en la Primera Guerra Mundial. Pasó cuatro años intentando recuperarse de esta herida $y$, después, las secuelas de este percance le acompañaron a lo largo de la vida.

En 1920 comenzó su etapa como maestro en un pequeño pueblo, con niños de entre seis y ocho años. A partir de sus inquietudes sociales y educativas, y también debido a sus propias limitaciones para poder hablar de manera continuada durante largo tiempo, se planteó algunos cambios en la dinámica del aula. Freinet inicia una formación pedagógica y cultural de marcado signo autodidacta. Lee a los autores marxistas, a los clásicos de la pedagogía - Rabelais, Montaigne, Rousseau, Pestalozzi - y a los psicólogos y pedagogos del momento. Viaja a Alemania y Rusia.

En los años veinte surgen de manera sucesiva las principales técnicas Freinet: el texto libre, la imprenta escolar, el diario escolar, la correspondencia interescolar y el fichero escolar cooperativo. En 1926, Freinet y Elise se casan e inician una colaboración que se prolongará durante cuatro décadas ${ }^{1}$. Un año más tarde Freinet escribe y publica su primer libro, dedicado a la exposición de las técnicas de la imprenta escolar. A partir de ese momento, inicia la constitución de un movimiento pedagógico de maestros centrado en la experimentación y difusión de las nuevas técnicas educativas, bajo la denominación de Cooperativa de la Enseñanza Laica - CEL.

Durante los años treinta, la propuesta freinetiana se consolidó y extendió. La CEL celebraba anualmente sus congresos, editaba revistas educativas y diverso material pedagógico, y promovía diferentes actividades en el ámbito de la formación de los maestros. Freinet se tropezó con el rechazo de los sectores más conservadores de St. Paul de Vence - su segundo destino en la enseñanza pública - $y$, como consecuencia de una serie de arbitrariedades de la administración, fue trasladado forzosamente. Tanto él como su mujer, también maestra, se negaron a aceptar el cambio forzoso de localidad. Ambos dimitieron de la enseñanza pública. A partir de ese momento, Freinet se planteó la necesidad de crear una escuela propia, que habría de ser, a la vez, un laboratorio de experimentación pedagógica y una iniciativa de cambio social progresista. No deja de ser una paradoja que uno de los mayores defensores de la escuela pública contemporánea se haya visto obligado a trabajar en una escuela de iniciativa privada, aunque con una vocación decididamente pública.

Durante los años treinta del siglo 20 , el movimiento Freinet tuvo una participación muy directa en la militancia antifascista y en el desarrollo de iniciativas de izquierdas para garantizar una enseñanza de calidad. Freinet viajó mucho en estos años, pronunciando conferencias tanto en Francia como en algunos otros países. Estas actividades aumentaron la influencia de las técnicas Freinet, que comenzaron a ser aplicadas en Bélgica, España y Suiza y, posteriormente, en un mayor número de países.

\footnotetext{
${ }^{1}$ Elise Freinet murió en 1983.
} 
En la Segunda Guerra Mundial, el movimiento Freinet fue desmantelado. Freinet ingresó en un campo de concentración, en el cual permaneció retenido año y medio. Allí preparó sus obras de madurez. Al ser liberado, formó parte de la Resistencia. En 1945, volvió a Vence y encontró su escuela y los almacenes de la CEL saqueados. Es la hora de la reconstitución del movimiento, que pronto iniciará su andadura. En 1947 abre sus puertas de nuevo la Escuela Freinet de Vence. En los años 1950 y 60, el movimiento Freinet vuelve a consolidarse como una fuerza pedagógica importante. La influencia internacional de Freinet se extiende. Durante los últimos años de su vida, Freinet siguió dedicado a la adaptación de nuevas técnicas educativas, atento a las últimas tendencias psicopedagógicas. El Instituto Cooperativo de la Escuela Moderna - Icem - continuó el trabajo propuesto por Freinet. La obra de Freinet está traducida a las lenguas más importantes. Los grupos de inspiración freinetiana se desarrollaron en muchos países, sobre todo de Europa, África y América central y del sur².

\section{El modelo pedagógico de Freinet: innovación educativa y progresismo sociopolítico \\ - Perspectiva sociopolítica}

Freinet coincide con los grandes postulados del activismo pedagógico de las primeras décadas del siglo 20. Sin embargo, lo que resulta específico en Freinet, respecto de otros precursores de la Escuela Nueva, es la perspectiva sociopolítica e ideológica marxista con la que analiza la evolución de la sociedad, la cultura y la educación de la primera mitad del siglo 20 , dentro de una crítica global del capitalismo. Frente al conservadurismo, al pretendido neutralismo apolítico y al utopismo progresista, Freinet se sitúa en la izquierda sindical y política. Desde esta perspectiva, el discurso y la práctica de Freinet conectan con las inquietudes ciudadanas y públicas del socialismo y del laicismo. La lucha en favor de la inclusión social y en contra las desigualdades debe trabajarse también desde una perspectiva pedagógica, para favorecer una educación popular y hacer de la escuela una herramienta al servicio de la ciudadanía crítica y participativa.

\section{- Ante la Escuela Nueva: herencia y ruptura}

Freinet se considera a sí mismo un heredero de la Escuela Nueva, pero también propugna romper con este movimiento debido a sus limitaciones y al marco pedagogista en el que se desenvuelve. Tras haberse interesado por clásicos como Montaigne, Rabelais, Rousseau y Pestalozzi, Freinet lee en 1922 L'école active, de Adolphe Ferrière, libro que le facilita el contacto posterior con las obras más importantes de los autores de la escuela nueva.

Freinet pertenece a la segunda generación de la escuela nueva, a aquella que ya no cree en el papel providencial de la escuela como agente de regeneración social. Las propuestas ideológicas y prácticas de Freinet supusieron a la vez una prolongación y un cuestionamiento profundo de los grandes innovadores de la Escuela Nueva, a los que Freinet se sentía unido de un modo auténtico y agradecido. Freinet era uno de ellos, en un cierto sentido, pero desde otra perspectiva Freinet era un revolucionario, un

\footnotetext{
${ }^{2}$ Para la biografía de Freinet y su movimiento, véase González-Monteagudo, 1988a, p. 19-111.
} 
iconoclasta, un comunista, un activista sindical, un maestro rural, un educador de la base. Es evidente que Freinet llevó a cabo un progresivo distanciamiento respecto de sus grandes maestros de la escuela activa. En la escuela nueva, Freinet criticó la pretendida centralidad de la actividad, el idealismo, el elitismo, la idea de una escuela alegre y atractiva, la mística romántica de la espontaneidad y libertad del niño, y la ausencia de una crítica social. Buscando una presentación simple de un enfoque alternativo a la escuela activa o nueva, Freinet propuso la etiqueta de escuela moderna para su movimiento, resaltando el trabajo educativo de base realizado mediante la cooperación.

Las diferencias entre los grandes teóricos de la escuela nueva y Freinet se evidencian en la crítica de la escuela. La crítica de la escuela tradicional adquirió en Freinet un matiz más político e ideológico, ausente en los primeros innovadores de la escuela activa o nueva - Decroly, Férrière, Montessori. Por ejemplo, Freinet rechaza los textos escolares no sólo porque empobrecen la actividad cognitiva de los alumnos y limitan la capacidad de exploración personal; también se opone a los libros de texto porque transmiten las ideologías nacionalistas y adormecen las conciencias, porque son un instrumento de domesticación y de reproducción social. Los libros de texto constituyen una herramienta ideológica y de sumisión a la sociedad y a los adultos, y exponen una moral falsa y patriotera que alienta el sentimiento nacional excluyente y las guerras.

\section{- Cooperación}

Freinet también es diferente de la primera gran generación europea de renovadores educativos porque concibe la cooperación educativa en toda su complejidad - maestros, alumnos, padres, asociaciones y grupos culturales -, promoviendo la investigación grupal de los educadores con vistas a la mejora de la enseñanza. La cooperación, entendida como gestión de la vida y del trabajo escolar por parte de los propios usuarios, fue probablemente, como señaló un educador italiano, lo más genuino, específico e indiscutible de la pedagogía de Freinet (Pettini, 1977).

Freinet trasciende la interpretación pedagógica de la cooperación, pues ésta resulta necesaria como herramienta que favorece los fines comunitarios y sociales. Desde esta perspectiva, la cooperación implica formas de gestión y de organización opuestas al capitalismo. Pedagógicamente, la cooperación supone la superación del individualismo, característico, por ejemplo, de los libros de texto.

\section{- Enfoque global de la educación}

Complejidad, crítica de la estrecha perspectiva cognitivista, defensa de las artes y de la estética, incorporación de las nuevas tecnologías de la época - el periódico, la radio, el cine -, vinculación al medio local, aprendizaje práctico orientado a la resolución de problemas, actividad manual, acción cooperativa, impulso democrático y ciudadano, experimentación pedagógica, viajes e intercambios, prensa, correspondencia, enfoque del lenguaje como instrumento de comunicación, elaboración de materiales didácticos por parte de educadores y educandos, estas son algunas de las contribuciones de Freinet, que muestran claramente tanto la continuidad como la ruptura respecto de los primeros grandes renovadores de la escuela europea. 
Estas contribuciones muestran un gran interés hacia los enfoques globales. La educación ha de ser pensada, practicada y valorada desde diferentes perspectivas. Hay que sumar las aportaciones de los diversos sectores y actores a la tarea educativa. La educación es un fenómeno social y cultural, y no sólo un proceso instructivo y cognitivo que se lleva a cabo en las escuelas (Saint-Luc, 2011).

Para progresar en la producción de conocimiento que sea útil para la práctica educativa, los educadores han de confiar en ellos mismos y en su capacidad de generar procesos de aprendizaje grupal. Esto debe ser la base de la formación permanente, del desarrollo profesional y de la propia innovación de la práctica educativa. Para esta tarea, la investigación experta, promovida por los científicos y pedagogos universitarios, no resulta una vía útil, porque el cientifismo, basado en la medición objetiva del rendimiento académico, no es capaz de valorar la contribución de una pedagogía que supone una transformación completa de los roles educativos, de las dinámicas de aprendizaje, de los procesos de construcción y apropiación del conocimiento.

La escuela moderna implica un replanteamiento de la función y el estatuto de la escuela desde un punto de vista social y cultural. Vinculación, pues, con el medio local, con las cuestiones importantes de la actualidad que son susceptibles de orientar y de dar contenido a los aprendizaje. Conexión de la escuela y de sus actores con las dinámicas culturales cercanas. Incorporación a la tarea educativa de las nuevas tecnologías del momento, como la radio, el periódico y el cine. Adaptación de las herramientas y ocupaciones laborales habituales en el medio social de los alumnos, para hacer del trabajo una actividad plenamente formativa, adaptada a las necesidades de los niños. De esta forma, la escuela será, por fin, un taller, y dejará de ser un templo. Freinet se maneja bien con las metáforas, con las descripciones sintéticas, con las imágenes que oponen dos concepciones pedagógicas o filosóficas de una manera gráfica, directa y fácilmente inteligible - el taller versus el templo; la escuela moderna contra la escolástica - aunque en ocasiones esto resulte algo simplista y reductor de una realidad más poliédrica.

La educación ha de construirse con la colaboración de todos los actores implicados. Los niños, los educadores, los padres, las asociaciones del medio local, las personas del mundo de la cultura, todos han de trabajar juntos, buscando acuerdos, sumando energías, ampliando los horizontes de aprendizaje de los educandos, desarrollando iniciativas sociales y culturales para ofrecer mejores condiciones educativas: menor número de alumnos por clase, mejores educadores, más posibilidades de innovación y de adaptación de la enseñanza a contextos particulares.

"Freinet propone una especie de esperanto de la pedagogía, conciliando Montessori, Decroly, Makarenko, Dewey [...], pero imprimiendo su propia marca" (F. Zurriaga, cit. en González-Monteagudo, 1988a, p. 408). La obra de Freinet es un lugar de encuentro y de convergencia de corrientes dispares e incluso contrapuestas. Freinet representa una síntesis entre el activismo y el reformismo pedagógicos de la Escuela Nueva europea y americana, que le facilitan la fuente de sus investigaciones estrictamente pedagógicas y en parte psicológicas), y la tradición marxista, socialista y anarquista, que le proporcionan el marco en el que situar las metas de la reforma educativa y social, articulada 
paralelamente a la experimentación didáctica, así como el concepto de trabajo como elemento motor de la sociedad y de la propia tarea educativa.

\section{- Internacionalismo y europeismo como horizontes}

En mayor medida que otros educadores, Freinet nos invita a adoptar una perspectiva europea, internacional y global de la cultura y de la educación, crítica con los tribalismos localistas y con los nacionalismos excluyentes, promotora de una democracia de los ciudadanos informados e ilustrados, defensora de los valores de la cultura, de la educación y de la paz. Una dimensión de la cooperación evocada previamente implica también la colaboración y el aprendizaje transnacionales: viajes de estudio al extranjero, búsqueda de experiencias educativas innovadoras más allá de las fronteras nacionales, intercambios, colaboración en la actividad sindical y en la formación docente, creación de movimientos de innovación educativa transnacionales. Ya en 1928 escribe Freinet: "Nuestro trabajo será decididamente internacional. La pedagogía actual no puede conocer fronteras y procuraremos derribar todos los obstáculos que las lenguas erigen entre los maestros del pueblo" (Célestin Freinet, cit. en Élise Freinet, 1977, p. 82).

La revista de la CEL incluía una sección de relaciones con el extranjero, que comprendía la correspondencia internacional en esperanto y un apartado de documentación internacional. En 1933, la correspondencia internacional en esperanto permitía los intercambios entre 250 centros escolares, que comunicaban a 2.000 alumnos franceses con más de tres amigos extranjeros. En este sentido, Freinet, prolongando las propuestas y experiencias de la escuela nueva, fue un gran precursor de una dimensión europea e internacional de la educación, que sólo pudo comenzar a perfilarse de una manera nítida en las dos últimas décadas del siglo 20, bajo el impulso de la unificación europea y de un espacio común europeo de la cultura y de la educación. En este contexto, la figura de Freinet nos invita a trascender los límites y las fronteras que se derivan de los estados nacionales, las lenguas, las culturas y los localismos.

Entre el reconocimiento agradecido a sus maestros y la crítica permanente de la sociedad y la escuela de su tiempo, Freinet, poeta aficionado y roussoniano por vocación, también fue, al mismo tiempo, un pedagogo contracultural y polémico, siempre insatisfecho con la sociedad en la que le tocó vivir, siempre queriendo ir más allá, para trascender los límites de un momento histórico europeo signado por la tragedia de la Gran Guerra y por el conservadurismo social y educativo, que combatió con una energía inmensa y una dedicación casi mística.

\section{Dos precedentes sobre la escritura infantil y el periódico escolar}

Freinet representa un cambio de paradigma en cuanto a la concepción del papel de la escritura de los niños en contextos escolares. Prolongando las contribuciones de autores y educadores como Tolstoi, O. Decroly y J. Dewey, Freinet redefine la posición de los niños en la escuela, promoviendo una educación centrada en la libre expresión y en la creación colectiva del conocimiento. Criticando los libros de texto, los ejercicios rutinarios, el memorismo superficial y la abstracción de los contenidos, Freinet abre nuevos caminos para el desarrollo de la creatividad y la autonomía de los escolares. En este enfoque 
renovado, conocido como Escuela Moderna, el texto libre, la imprenta escolar y el periódico escolar han desempeñado una función decisiva, como técnicas que han hecho posible, en las condiciones habituales de las escuelas populares, el desarrollo de una educación adaptada a las necesidades de desarrollo de los niños.

En esta sección voy a evocar dos precedentes importantes que se caracterizaron por la importancia otorgada a la expresión escrita de los niños y, en parte, por la divulgación de los textos producidos por los propios niños a través de diferentes técnicas y herramientas de socialización y difusión de las producciones infantiles. Entre estas técnicas hay que mencionar la imprenta escolar y el periódico escolar. Estos precedentes constituyen un ámbito poco explorado de la Historia de la educación, al menos si consideramos la perspectiva específica de la libre expresión infantil y del estatus de la escritura infantil dentro del contexto de la evolución de las prácticas educativas contemporáneas.

El primer antecedente que quiero evocar se refiere al escritor y educador ruso Tolstoi, creador de la escuela de Yasnaia Poliana. Tolstoi valoró, como él mismo indica, "la razón de escribir y lo que hay de bello en el arte de escribir [...] el arte, la belleza de expresar la vida en palabras y la fascinación que de ello se desprende" (cit. en Vigotski, 1982, p. 73). El propio Vigotski comenta el procedimiento propuesto por Tolstoi para la composición, basado en las experiencias con niños campesinos, compuesto por tres normas: proponer una gama de temas amplia y variada; dar a leer a los niños composiciones de otros niños; y no hacer correcciones sobre la ortografía o la caligrafía. En Tolstoi encontramos un ejemplo de la nueva sensibilidad que se va abriendo paso en relación con la expresión escrita infantil.

En su artículo titulado "¿Quién debe enseñar a escribir: los niños del campo a nosotros, o nosotros a los niños del campo?" Tolstoi se hacía una pregunta radical y profunda. Al responder a esta pregunta eligiendo la primera opción, el educador ruso concedió un importante protagonismo a la infancia en la escritura (Vigotski, 1982, p. 7185). En cierto modo, al igual que Freinet lo haría más tarde, Tolstoi estaba reivindicando una cierta deconstrucción de la escuela, una "negación de la escuela como lugar", como indica Trilla (1976, p. 72). Al hacerlo, contribuyó a poner en el centro del discurso y de la práctica educativas el mundo de los niños, sus necesidades, intereses y formas de expresión.

El segundo precedente se lleva a cabo en Bélgica, por iniciativa de Ovide Decroly, quien tuvo sobre Freinet una influencia decisiva. En efecto, Decroly promovió en l'École de l'Ermitage el uso de la imprenta para confeccionar un diario con los textos producidos por los alumnos. El uso de la imprenta en contextos educativos tenía ya los precedentes de abad Louis Dumas, hacia 1730, y de Paul Robin, hacia 1890. El propio Freinet escribió que "determinados periodistas [...] se han dedicado a buscar en la historia pedagógica precedentes que borren a nuestra iniciativa [de la imprenta escolar] sus ventajas de invención y novedad" (Freinet, 1977, p. 15).

En realidad, Freinet solo reconoce el precedente de Decroly, que publicó, junto a sus alumnos, el Courrier de l'École, iniciado en 1925 - aunque fue anticipado por L'écho de l'Ecole, en 1917, aunque en esta primera iniciativa la impresión del periódico se realizaba 
fuera de la escuela, sin la participación de los alumnos. De Decroly recogió Freinet los centros de interés, adaptados bajo el nombre de con lejos de interés, y el método global de lectura, reformulado bajo la etiqueta de método natural de lectura. La relación entre teoría y práctica propugnada por Decroly fue decisiva para Freinet, que valoraba también las experiencias llevadas a cabo en la École de L'ermitage, fundada en 1907 por el pedagogo belga ${ }^{3}$.

\section{La escritura libre, la imprenta, el periódico escolar y la correspondencia}

La educación que propone Freinet es una educación para el trabajo (Freinet, 1971). Para ello, la escuela debe adoptar la forma del taller. En sus obras, Freinet plantea dos tipos de talleres. Los primeros estarían dedicados al trabajo manual de base, al cual se dirige el niño de manera espontánea: trabajo agrícola y cría de animales; herrería y carpintería; hilados, tejidos, costura, cocina y quehaceres domésticos; construcción, mecánica y comercio. El otro tipo de talleres tiene que ver con la actividad evolucionada, socializada e intelectualizada: conocimientos y documentación; experimentación de todo tipo; creación, expresión y comunicación escritas; y creación y comunicación artísticas.

El diario escolar, como vehículo de construcción colectiva del conocimiento, de difusión de la escritura libre y de edición cooperativa mediante la imprenta escolar, ha de ser contextualizado dentro del segundo tipo de talleres, y solo encuentra su pleno sentido, social y pedagógico, en ese contexto global de un modelo pedagógico integral y complejo. Pero antes de comentar las técnicas del texto libre, el diario escolar y la correspondencia, voy a referirme al papel que desempeñó la escritura en la personalidad y en la obra de Freinet.

\section{La escritura en Freinet}

Parto de la siguiente hipótesis: la centralidad que Freinet otorgó a la libre expresión del niño mediante la escritura, y otras formas expresivas, como la pintura, el modelado, la danza y la música, se puede comprender mejor investigando la propia posición de Freinet ante la escritura. El propio Freinet ha exagerado la importancia de su herida de guerra en el pulmón para avanzar en la creación y desarrollo de métodos de educación activa. Pero creo que hay que resaltar de manera primordial el interés de Freinet hacia el cambio social y su interés hacia la escritura personal. Freinet mantuvo diarios personales desde la adolescencia, y continuó con los diarios durante el período de su formación como maestro y de la segunda guerra mundial. Posteriormente, prolongó esta actividad con sus diarios de clase, mantenidos a lo largo de cuatro décadas.

Célestin Freinet amaba la escritura y se dedicó a ella durante más de 40 años con tenacidad, orgullo, método y evidente capacidad para comunicar con diferentes y cambiantes audiencias. Los escritos de Freinet sorprenden por su variedad y por su amplitud temática y expositiva. El propio Freinet declaraba en 1962 haber escrito unas 50.000 páginas, a lo que habría que añadir, además, la correspondencia mantenida por

\footnotetext{
${ }^{3}$ Sobre la historia de los diarios escolares realizados por los niños y jóvenes, pueden consultarse los trabajos de Corroy (2005), Gonnet (1988) y Poslaniec (1990).
} 
Freinet con centenares de maestros y pedagogos, así como sus diarios de clase, que inició poco después del comienzo de su carrera profesional.

No hay que olvidar que la variedad de actividades de Freinet le conducía a difundir su obra no sólo mediante libros y artículos. La correspondencia, los viajes, los cursillos y los congresos fueron decisivos a la hora de completar y divulgar sus propuestas. Según diferentes exigencias y circunstancias, Freinet, solo, con su esposa Elise o con otros colaboradores, refundía sus ideas en nuevas producciones textuales, adaptándolas a diferentes formas, como cartas, conferencias, programas, cursos de formación, artículos, libros, dichos de Mateo y monografías. Sin duda, Freinet luchó por encontrar una escritura personal y por crear una voz y una retórica textual coherentes con sus propósitos políticos, ideológicos, pedagógicos.

Creo que conviene distinguir cuatro grandes etapas en la escritura de Freinet, separadas por cambios profesionales e históricos y conectadas con las diferentes revistas en las que publicó. La primera etapa va de 1921 a 1926, mientras colaboraba en las revistas Clarté y L'école Émancipée, con artículos sobre Pestalozzi, los viajes a Rusia y Alemania, la crítica de la escuela y las propuestas de renovación escolar. Esta primera etapa supone un período de intensa formación pedagógica. La segunda etapa transcurre de 1927 a 1932, e incluye unos 60 artículos publicados en el boletín de la CEL. También en esta etapa publica sus dos primeros libros: L'imprimerie à l'école y Plus de manuels scolaires. Es un período de creación, consolidación y difusión de las técnicas Freinet. La tercera etapa está vinculada a los artículos publicados, en torno a 180, en la revista L'Éducateur Prolétarien.

En esta etapa profundiza en las cuestiones metodológicas, la difusión internacional de la pedagogía Freinet, el compromiso político de izquierdas durante el Frente Popular y la experiencia pedagógica de la escuela Freinet en Vence. Durante este período también publica las Brochures d'éducation nouvelle populaire - BNEP -, a las que Freinet contribuye con seis títulos dirigidos a los maestros. Tras el paréntesis de la retención en varios campos de concentración y el período de la clandestinidad, la cuarta y última etapa abarca desde 1943 hasta su muerte en 1966. Tras el paréntesis de la guerra, Freinet continúa una frenética actividad de escritura y divulgación. En este prolífico período publicó, en la revista L'Educateur y en otras revistas, algo más de 1.500 artículos. También redactó 17 folletos de las Brochures, 18 libros de la colección Bibliothèque de l'Ecole Moderne y 16 libros, algunos de ellos fueron recopilaciones de artículos. Entre los libros de este período, destaco los siguientes: Conseil aux parents, L'ecole moderne française, Les techniques Freinet de l'ecole moderne, L'education du travail y Essai de psychologie sensible.

La escritura pedagógica de Freinet es imprecisa, ambigua, caprichosa, metafórica, parabólica y poética (González-Monteagudo, 1988a). Y, a pesar de todo ello, o quizá gracias a todo ello, sigue seduciendo y cautivando, más allá de las críticas realizadas desde una perspectiva científica. Resulta evidente que uno de los criterios principales por los que debemos de valorar una obra escrita - en este caso, en el campo educativo - tiene que ver con la capacidad de comunicación, con la captación de audiencias amplias y con 
la habilidad para movilizar a las personas y a los grupos de cara a la transformación y mejora de la práctica educativa.

El pensamiento y la escritura de Freinet contienen un marcado sesgo naturalista. En particular se trata de una suerte de ruralismo naturalista (González-Monteagudo, 2010). Hay que tener en cuenta los orígenes rurales de Freinet, que reivindica la ruralidad, caracterizada por la sencillez, la simplicidad y el buen sentido. Freinet recurre a las experiencias de la vida diaria, particularmente a las experiencias en el medio rural, pretendiendo establecer analogías entre procesos naturales y procesos educativos. Por ejemplo, la semilla que crece, para ilustrar el desarrollo humano; el caballo que no tiene sed, para comentar la ausencia de motivación escolar; el arroyo como símbolo de devenir personal y social.

Con frecuencia Freinet recurre a los conceptos de naturaleza y de desarrollo natural. En este terreno, es un pedagogo que confía en las virtudes del medio natural como principal instrumento de equilibrio, salud y formación. Recomienda y practica el naturismo, el vegetarianismo, la hidroterapia, la helioterapia, los ejercicios físicos y una medicina natural, incluso la oposición a las vacunas. Freinet es, sin duda, un ecologista avant la lettre. Para Freinet, los individuos poseen un potencial de vida. Se trata de una concepción optimista no sólo de los seres humanos, sino del conjunto de los seres vivos: "Tomo la vida en su movimiento, sin prejuzgar de su origen ni de sus fines. El individuo es impulsado por su propia naturaleza a recorrer su ciclo normal de vida, a realizar su destino" (Freinet, 1977b, p. 12). En este aspecto, Freinet está influido por el vitalismo filosófico de $\mathrm{H}$. Bergson. Pero el creador de la Escuela Moderna hace de este vitalismo naturalista, además, un estilo de vida. Así, por ejemplo, fomentó las prácticas naturistas en su escuela de Vence, basadas en la higiene natural y en un programa dietético. En todas estas cuestiones, se nos revela el perfil idealista, ascético y rigorista de Freinet, que desarrolló su labor bajo la consigna de una ética muy exigente.

La escritura pedagógica freinetiana es profundamente experiencial, y está vinculada a un proyecto personal y profesional basado en el militantismo pedagógico y político. Salvadas las diferencias históricas e ideológicas, el proyecto de Freinet remite al legado de Pestalozzi, pedagogo por el que Freinet sintió una atracción profunda. Los dos educadores se entregaron a sus proyectos pedagógicos con una pasión vital profunda. "Todo aquello de que hablo, lo he visto, escribió Pestalozzi. Y he hecho una gran parte de lo que aconsejo. He renunciado a los placeres de la vida para consagrarme a mi ensayo de educación del pueblo" (Pestalozzi, cit. González-Monteagudo, 1988a, 116).

Texto libre, imprenta escolar y diario escolar: técnicas al servicio de la expresión profunda y de la comunicación.

Freinet fue muy consciente de la importancia histórica y teórica del cambio de paradigma que comenzó a desarrollar cuando propuso un modelo educativo centrado en la escritura libre de los niños. Disponiendo de una documentación muy amplia en sus archivos, producto de los envíos de cientos de escuelas, Freinet señaló su falta de tiempo para trabajar sobre esta inmensa colección de diarios escolares: 
Habríamos querido comenzar un examen serio y metódico de los centenares de diarios escolares que recibimos y que constituyen documentos únicos en la pedagogía mundial. Las necesidades materiales no nos lo han permitido... Pero no perdemos de vista la importancia psicológica y pedagógica de nuestra nueva actividad, ni las perspectivas que se abren ante nosotros. (C. Freinet, cit. Madeleine Freinet, 1977, p. 176)

Actualmente contamos con algunos trabajos históricos que reproducen algunos diarios escolares del aula del propio Freinet y analizan críticamente sus contenidos y el papel de esta técnica dentro del conjunto de propuestas metodológicas de Freinet. La publicación más importante ha sido realizada por M. Barré (1997), amigo y compañero de Célestin Freinet, quien ha recogido extractos de periódicos escolares del período comprendido entre 1926 y 1940. Por su parte, Chevenez (2007) ha comparado algunos diarios escolares realizados por Freinet en la década de los años 20 del siglo pasado con diarios escolares de 2005 y 2006.

Con la creación de las técnicas del texto libre, imprenta escolar y diario escolar, Freinet está proponiendo una nueva perspectiva de trabajo escolar, centrado en la liberación del niño de los poderes opresivos y del autoritarismo - familiar, escolar, social e ideológico - que lo limitan:

Me gustaría, sobre todo - escribe Freinet - contribuir a desarrollar el sentido común de los hijos de los trabajadores. Espero que cuando sean mayores, mis alumnos se acuerden de lo que son las hojas impresas: vulgares pensamientos humanos, sujetos por desgracia a error. $Y$ de igual manera que ellos critican hoy sus modestos impresos, deseo que sepan leer y criticar, más tarde, los periódicos que les ofrezcan. (Célestin Freinet, cit. en Elise Freinet, 1977, p. 54)

Es decir, Freinet propone una alfabetización crítica de los medios de información más modernos de su tiempo: la prensa, la radio y el cine.

En otras publicaciones he descrito el modelo didáctico de Freinet, desde una perspectiva global, que implica una profunda interconexión entre las técnicas educativas así como una perspectiva cooperativa en el trabajo escolar y docente (GonzálezMonteagudo, 1988a; 1989).

El elemento decisivo que caracterizó la evolución de las técnicas educativas fue la apuesta de Freinet por la colaboración con los maestros. Criticando a Montessori, Freinet indicó que él no se había limitado a patentar un nuevo método educativo, sino que se propuso compartir la experimentación de las nuevas técnicas. ${ }^{4}$

Hay que aclarar que para Freinet, en el contexto de los primeros cursos de la escuela primaria, "el diario escolar método Freinet es una recopilación de los textos libres realizados e impresos día a día según la técnica Freinet y agrupados a fin de mes con una cubierta especial para los abonados y corresponsales" (Freinet, p. 19, 1978). Sin embargo, para cursos más avanzados, Freinet prefiere la idea, más compleja, de la edición de un periódico escolar, imitando y adaptando el modelo de los periódicos para

\footnotetext{
${ }^{4}$ Véase Madeleine Freinet, 1997, p. 128-130.
} 
adultos. En la trayectoria de Freinet, la propuesta del texto libre posee una importancia indudable, y esta técnica constituye la base del periódico escolar en sus inicios.

El texto libre constituye un documento que nos permite el conocimiento profundo de la vida del niño, a la vez que supone una herramienta que hace posible el desarrollo del pensamiento infantil, de una manera libre y creativa. El diario escolar y la imprenta exigen la colaboración de los niños, para elaborar un producto que pueda ser difundido y compartido, a través principalmente de la correspondencia escolar y de la distribución en el medio local de la escuela. Estas técnicas de aprendizaje activo, cooperativo y vinculado al medio de los alumnos, tienen una estrecha relación con las propuestas pedagógicas de John Dewey y con los modelos posteriores de investigación en la escuela (GonzálezMonteagudo, 1989).

\section{Influencias de Freinet y actualidad de los diarios escolares}

La influencia de Freinet en las prácticas educativas contemporáneas es amplia y tiene un alcance internacional. En los últimos años se están publicando trabajos históricos de gran calidad, que rastrean la difusión de las técnicas Freinet en diferentes ámbitos geográficos. En el caso español, los estudios recientes de Herández Huerta (2012) y de Jiménez Mier (2012) ofrecen, por vez primera, una información muy completa sobre la influencia de Freinet en la educación española, fundamentalmente entre 1926 y 1939. Y en esta misma revista, Hernández Huerta y Hernández Díaz (2011) han publicado un extenso trabajo sobre esta temática. Una contribución también muy relevante procede de Jiménez Mier (1996), quien ha editado, en una cuidada obra, la revista Colaboración. La imprenta en la escuela, publicada por el grupo español de maestros freinetianos en los años 1935 y 1936. Esta obra es una fuente de información importante en relación con la escritura, la imprenta y los periódicos escolares, con una doble referencia a los alumnos y a los maestros.

Como una muestra de esta influencia de Freinet, voy a mencionar el caso de Italia, entre otros posibles (González-Monteagudo, 1997). El Movimento di Cooperazione Educativa - MCE - es el grupo de renovación pedagógica más importante del panorama pedagógico italiano de la segunda mitad del siglo 20. El grupo original lo constituyó un grupo de maestros italianos orientados por un ideal democrático. Se trataba en la mayor parte de los casos de combatientes antifascistas, que intentaron luchar, esta vez de manera pacífica, contra el atraso pedagógico de la escuela italiana. Pretendieron llevar al aula los ideales de libertad, igualdad y apertura que consideraban irrenunciables en la sociedad italiana surgida de la guerra contra el fascismo. El grupo fue fundado en 1951, un año después de que Freinet visitara Florencia, por invitación de Ernesto Codignola, para exponer sus técnicas. Al año siguiente, en 1952, se llevó a cabo el primer congreso, con la asistencia de sesenta y dos miembros, evento al que acudió Freinet ${ }^{5}$.

El objetivo inicial de este grupo era la experimentación en el contexto específico italiano de las Técnicas Freinet, todo ello en base a la enseñanza individualizada y globalizada, que debería de partir de la experiencia directa y concreta del niño, mediante la cooperación entre maestro y alumnos. El grupo italiano evolucionó hacia una

\footnotetext{
${ }^{5}$ Sobre Freinet y sus relaciones con los italianos, véase González-Monteagudo (1988a).
} 
concepción más abierta, superando la dimensión meramente técnica y didáctica del Movimiento para reivindicar los conceptos nucleares de pedagogía popular y de cooperación educativa. Una década más tarde, los acontecimientos de mayo de 1968 sacudieron fuertemente las estructuras de la escuela italiana. Los miembros del MCE asumieron una orientación política en sus planteamientos educativos y radicalizaron el discurso pedagógico anterior.

EI MCE ha realizado un importante trabajo en el ámbito didáctico a lo largo de todos estos años, particularmente en los ámbitos de la lengua, las ciencias sociales, las matemáticas, la metodología investigativa y la educación corporal. Su contribución a la renovación de la escuela italiana es innegable, a pesar de las dimensiones relativamente pequeñas del grupo y de la influencia necesariamente limitada de sus componentes.

Dentro de este grupo, el trabajo didáctico y las publicaciones de Mario Lodi nos ilustran sobre la importancia del diario escolar como técnicas educativa. Lodi parte de una concepción positiva sobre la infancia. Lodi es un gran optimista pedagógico, puesto que confía en el niño de una manera incondicional. Si algo no funciona en el aula, no es por culpa del niño. Al hablar del niño, se refiere al "niño eterno, libre, auténtico, rico en vitalidad y en fantasía que se manifiesta a sí mismo" (Lodi, 1974, p. 10). Si sabemos crear las condiciones más óptimas en el aula, "el alumno poco a poco se convierte en una inagotable mina de motivos; se trata de desarrollar los más válidos, es decir, los más próximos a los intereses de los niños, que ellos mismos sienten y buscan (Lodi, 1974, p. 127).

Así, desde los intereses de los niños, se llega al diálogo, al estudio de la lengua, al uso de la imprenta, a la socialización del trabajo, a la pintura y la estética, al juego dramático y el canto, a las observaciones, y, en fin, al estudio de la naturaleza y de las matemáticas. Lodi señala explícitamente que sus alumnos, al poder elegir libremente, tienden a preferir sobre todo el periódico escolar, la correspondencia y la pintura, actividades que satisfacen la necesidad de expresión y de comunicación de la experiencia personal (Lodi, 1974). El psicólogo y dibujante italiano Francesco Tonucci publicó un libro con los contenidos de los diarios escolares del aula de Lodi y con comentarios sobre el modelo pedagógico que da sentido a la práctica del periódico escolar (Tonucci, 1981).

En los últimos años, las nuevas tecnologías han cambiado de manera radical las formas anteriores de realización de los periódicos escolares. Los medios disponibles para la elaboración de los contenidos, para la edición y para la difusión ofrecen nuevas nuevas posibilidades, aunque la dimensión formativa y motivadora del diario escolar siguen siendo similares actualmente y en los inicios de la técnica. También importa resaltarla dimensión internacional de los periódicos escolares, facilitada por las nuevas tecnologías de edición, por la comunicación digital a distancia y por el aumento de los intercambios educativos entre escuelas (Chevenez, 2007; Tremuth y Scheuren, 1995).

\section{Referências}

ACKER, Victor. Célestin Freinet (1896-1966): I'histoire d'un jeune intellectuel. Paris: L'Harmattan, 2006. 
BARRÉ, Michel. Avec les élèves de Célestin Freinet: extraits des journaux scolaires de sa classe à Bar-sur-Luop, Saint-Paul et Vence de 1926 à 1940. Paris: Institut National de Recherche Pédagogique, 1997.

BRULIARD, Luc; SCHLEMMINGER, Gerald. Le mouvement Freinet: des origines aux années quatre-vingt. Paris: L'Harmattan, 1996.

CHEVENEZ, Odile. Journaux scolaires à l'ère d'Internet: problèmes, enjeux, concepts mémoire de maîtrise. Paris: Université de Paris 3 Sorbonne Nouvelle, 2007.

CLANCHÉ, Pierre. El texto libre, la escritura de los niños. Madrid: Fundamentos, 1978.

CLANCHÉ, Pierre; Debarbieux, Éric; Testanière, Jacques (eds.). La pédagogie Freinet, mises à jour et perspectives. Bordeaux: Presses Universitaires de Bordeaux, 1999.

CORROY, Laurence. Une histoire ancienne: les journaux lycéens au $19 \mathrm{e}$ siècle. Revue Média Morphoses, n. 13, 2005, p. 26-29.

FREINET, Célestin. La educación por el trabajo. México: FCE, 1971.

FREINET, Célestin. El diario escolar. Barcelona: Laia, 1977a.

FREINET, Célestin. Ensayo de psicología sensitiva: reeducación de las técnicas de vida sustitutivas, v. 2, Madrid: Villalar, 1997b.

FREINET, Célestin. El texto libre. Barcelona: Laia, 1978.

FREINET, Élise. Nacimiento de una pedagogía popular. Barcelona: Laia, 1977.

FREINET, Madeleine. Élise et Célestin Freinet. Tome 1. Souvenirs de notre vie, 18961942. Paris: Stock, 1997.

GONNET, Jacques. Journaux scolaires et lycéens. Paris: Retz, 1988.

GONZÁLEZ-MONTEAGUDO, José. La pedagogía de Célestin Freinet: contexto, bases teóricas, influencia. Madrid: Ministerio de Educación/Cide, 1988a. Disponible en $<$ http://www.educacion.es/cide/espanol/publicaciones/colecciones/investigacion/col012/col 012pc.pdf.> Acceso en: 12 maio, 2012.

GONZÁLEZ-MONTEAGUDO, José. Célestin Freinet, un precursor de la investigación en la escuela. Aspectos generales de su Didáctica. Investigación en la Escuela, Universidad de Sevilla, n. 6, 1988b, p. 51-61.

GONZÁLEZ-MONTEAGUDO, José. Célestin Freinet, un precursor de la investigación en la escuela. Las técnicas educativas y la organización del aprendizaje. Investigación en la escuela, n. 7, 1989, p. 49-67.

GONZÁLEZ-MONTEAGUDO, José. Aportaciones de Mario Lodi a la innovación pedagógica. Argumentos teóricos y experiencias realizadas. Cuestiones Pedagógicas, Universidad de Sevilla, n. 13, 1997, p. 27-38.

GONZÁLEZ-MONTEAGUDO, José. La pedagogía Freinet en España después de 1939. In: ROMERO DE ÁVILA, Sebastián Gertrúdix. Simón Omella: el maestro de Plasencia del Monte. Zaragoza: Diputación General de Aragón, 2002, p. 173-178.

GONZÁLEZ-MONTEAGUDO, José. L'écriture pédagogique de Célestin Freinet, entre rhétorique littéraire et innovation éducative. In: ZAMBRANO, Armando (ed.). Littérature et formation. Cali: Universidad Santiago de Cali, 2009, p. 70-93.

GONZÁLEZ-MONTEAGUDO, José. Naturaleza, ruralidad y educación en Célestin Freinet, 
Educação e Contemporaneidade, Salvador: Universidade do Estado da Bahia), n. 36, 2010, p. 69-78.

HERNÁNDEZ HUERTA, José Luis. Freinet en España (1926-1939). Valladolid: Castilla, 2012. DVD.

HERNÁNDEZ HUERTA, José Luis; HERNÁNDEZ DÍAZ, José María. Freinet na Espanha (1926-1939). História da Educação, Porto Alegre: Asphe, v. 16, n. 36, 2012, p. 9-51.

JIMÉNEZ MIER, Fernando. Freinet en España: la revista Colaboración. Barcelona: EUB, 1996.

JIMÉNEZ MIER, Fernando. ¡Viva la imprenta! Orígenes de la educación Freinet en España. México-España: Tanteo, 2012.

LAFON, Delphine. Célestin Freinet ou la révolution par l'école: mémorie de maîtrise. Nice: Université de Nice/Sophia-Antipolis, 1999.

LODI, Mario. Crónica pedagógica. Barcelona: Laia, 1974.

LODI, Mario. Insieme: un diario de clase. Barcelona: Laia, 1982.

LULL MARTÍN, Enrique. Prensa escolar y educación católica en vísperas de la II República - la revista Auras de Colegio, de los jesuitas de Valencia (1917-1936). Anales de Historia Contemporánea, n. 15, 1999, p. 339-348.

PETTINI, Aldo. Célestin Freinet y sus técnicas. Salamanca: Sígueme, 1977.

POSLANIEC, Christian. D'où vient le journal scolaire? Documents du Nouvel Éducateur, n. 212, 1990, p. 2-5.

SAINT-LUC, Florence. Pédagogie Freinet et pensée complexe. Revue La Recherche en Éducation, n. 6, 2011, p. 39-55.

TONUCCI, Francesco. Viaje alrededor del El Mundo: diario de Mario Lodi y sus alumnos. Barcelona: Laia, 1981.

TREMUTH, Fernand; SCHEUREN, Jos. Le journal scolaire international, 1995. Disponible: <http://www.script.lu/documentation/pdf/publi/bull10/tremuth.pd> Acceso en: 1 set., 2012.

TRILLA, Jaume. Negación de la escuela como lugar. El Viejo Topo, extra n. 5, p. 68-74, 1976.

VYGOTSKI, Lev Semionovich. La creación literaria en la edad infantil. Infancia $y$ Aprendizaje, n. 17, 1982, p. 71-85.

JOSÉ GONZÁLEZ MONTEAGUDO es profesor en el Departamento de Teoría de la Historia da Educación e Pedagogía Social - Facultad de Ciencias de la Educación Universidad de Sevilla.

Contacto: Rúe Pirotecnia, s/n - 41013 - Sevilla - España.

E-mail: monteagu@hotmail.com.

Recebido em 10 de agosto de 2012

Aceito em 22 de dezembro de 2012. 